\title{
The orthodox therapy of cardiovascular diseases integrated by ozone-therapy is able to normalize the redox system*
}

\author{
Velio Bocci $^{1 \#}$, Emma Borrelli ${ }^{2}$, Iacopo Zanardi ${ }^{3}$, Valter Travagli ${ }^{3 \#}$ \\ ${ }^{1}$ Dipartimento di Fisiologia, Università degli Studi di Siena, Siena, Italy \\ ${ }^{2}$ Dipartimento di Biotecnologie Mediche, Università degli Studi di Siena, Siena, Italy \\ ${ }^{3}$ Dipartimento di Biotecnologie, Chimica e Farmacia, Università degli Studi di Siena, Siena, Italy \\ Email: " velio.bocci@unisi.it, ”valter.travagli@unisi.it
}

Received 24 March 2013; revised 28 April 2013; accepted 15 May 2013

Copyright (c) 2013 Velio Bocci et al. This is an open access article distributed under the Creative Commons Attribution License, which permits unrestricted use, distribution, and reproduction in any medium, provided the original work is properly cited.

\begin{abstract}
Cardiovascular diseases such as chronic limb ischemia, cardiomyopathies and stroke represent the first cause of death. Moreover, type-II diabetes, chronic obstructive pulmonary disease and age-related macular degeneration are also progressive pathologies complicated by a chronic inflammation that might be able to maintain progressive chronic oxidative stress. Orthodox medicine has provided excellent drugs which slow down the progression of these diseases but minimally reverse the oxidative stress conditions. Administration of antioxidants is unable to balance the oxidant excess. Today, all the biochemical and molecular mechanisms of ozone therapy have been clarified and it has been demonstrated that ozone therapy can reactivate the fundamental Nrf2 system and be able to restore the innate antioxidant defense mechanisms composed of several highly protective enzymes. This paper proposes to integrate the orthodox treatment with ozone therapy for improving clinical results.
\end{abstract}

Keywords: Chronic Oxidative Stress; Ozone-Therapy; Nrf2-Keap1; Antioxidant Response; Integrative Medicine

\section{INTRODUCTION}

Cardiovascular diseases, though preferentially affect either the heart, or the brain, or/and the leg arterial vessels, are due to a systemic pathological alterations of the

\footnotetext{
"Funding: The writing of this paper was not supported by any fund. Competing financial interests: The authors declare no competing financial interests.

${ }^{\#}$ Corresponding author.
}

vascular system. The pathogenetic mechanism of the endothelial dysfunction is further aggravated by a chronic oxidative stress [1]. While the problem of hyperglycemia and related effects can be corrected by effective antidiabetic drugs, the problem of oxidative stress remains unsolved because administration of antioxidants is minimally effective. The restorative integration of ozonetherapy offers the unique possibility of normalizing the redox system because one of the ozone messengers is able to activate the innate defence system, thus providing the crucial antioxidants.

The final purpose of the medical therapy is to achieve a real "cure" of the patient's illness. This is not always possible especially when the pathology is complex and due to multiple causes. Cardiovascular diseases such as myocardial infarction, stroke and peripheral obstructive arterial disease (POAD) are the first cause of death and represent a paradigmatic example as they are due to micro- and macro-endothelial dysfunction [2], atherosclerosis, hypertension [3,4], alteration of haemorheological factors, impaired NO availability and increased release of thromboxane A2 and endothelins [5,6]. Moreover, chronic smoking and a concomitant obesity and type 2 diabetes with the release of advanced glycation end products (AGEs) and deleterious adipokines (resistin, II-1, II-6, and TNF-alpha) will further aggravate the pathology [7]. An analysis of oxidative markers has clearly established the progress of a chronic oxidative stress due to an excessive generation of reactive oxygen and nitrogen species (ROS, RNS) from mitochondria, neutrophil NADPH oxidase and from the five NOX isoforms active in vascular tissues [8-10]. Cells become unable to counteract them with appropriate antioxidants.

Orthodox medicine has provided a number of effective drugs such as statins, angiotensin II receptors blockers, thiazide diuretics, beta-blockers, anticoagulants, prosta- 
cyclin analogues, some of which possess ancillary antioxidant properties. Administrations of antioxidants (vitamins $\mathrm{C}$ and $\mathrm{E}, \beta$-carotene) have failed to demonstrate a beneficial effect on cardiovascular morbility and mortality most likely because it is a passive modality and the real problem is inside the cell $[1,11,12]$. During the last decade it has become evident that dietary interventions, caloric restriction and a modest physical exercise may be useful but insufficient and it is indispensable to integrate the effective drug medication with a procedure able to selectively enhance the somewhat inhibited innate defensive system.

\section{MATERIALS AND METHODS}

\section{The Chronic Oxidative Stress Can Be Corrected by Using Ozone-Therapy}

Among the numerous complementary methods, only one is specifically able to correct the chronic oxidative stress. Preclinical [13] and clinical [14-16] studies performed with ozone-therapy have been performed in many countries and in Germany more than one million sessions are successfully held every year without any side effects.

Ozone, like other gases as $\mathrm{NO}, \mathrm{CO}, \mathrm{H}_{2} \mathrm{~S}$ and $\mathrm{H}_{2}$, although intrinsically toxic, when properly used in well determined small concentrations, has become important medical gases [17-19]. Usually 100 - $150 \mathrm{ml}$ of blood of the patient, anticoagulated with Na citrate, are collected in a sterile glass ozone-resistant bottle and an equal volume of a gas mixture $\left(96 \% \mathrm{O}_{2}-4 \% \mathrm{O}_{3}\right)$ is added at a precisely determined ozone concentration within 0.21 $0.84 \mathrm{mM}$ per $\mathrm{ml}$ of blood [20]. The ozonated blood is then infused into the donor patients within 2 - 3 min. The initial dose is the minimal and, for avoiding any side effects, is slowly upgraded up to $0.84 \mathrm{mM}$ throughout the necessary 30 - 40 sessions, twice weekly. The axiom: "start low, go slow" proves to be ideal and under these conditions, ozone behaves as an acceptable stressor [20]. Indeed ozone-therapy induces a series of graduated small oxidative stresses acting on all organs and able to reactivate the potent defence system, which counteracts the deleterious chronic oxidative stress induced by chronic inflammatory diseases.

The high reactivity and solubility of ozone in the water of plasma allows its exhaustion in one min while it generates two crucial messengers such as $\mathrm{H}_{2} \mathrm{O}_{2}$ and 4-hydroxynonenal (4-HNE), finally responsible for eliciting the well defined biochemical [16] and molecular reactions responsible for the biological activities. 4-HNE readily forms an adduct with the Cys34 of albumin or with glutathione and this compound is consequently be able to reach most of cells of the body and to reactivate the antioxidant defences.

\section{DISCUSSION}

\subsection{The Real Molecular Mechanisms of Antioxidant Activation}

Alkenal adducts are able to react with the Kelch-like ECH-associated protein 1 (Keap1)-NF-E2-related factor 2 (Nrf2) system that is present in the cell cytosol with the role of antagonizing oxidative and electrophilic insults [20-25]. In detail, Keap 1 is a protein molecule with many -SH groups that are important for the repression of Nrf2 activity [26]. Normally, the complex Nrf2-Keap1 has a half life of about 20 min because Keap1 is readily ubiquitinated and digested in the proteasome. However, the alkenal interaction with both Cys 272 and 288 of Keap-1 allows the release of Nrf2, which escapes proteasomal degradation and translocates into the nucleus, heterodimerizes with a small Maf protein and binds to the Antioxidant Response Element (ARE or EHRE) on DNA [21,22,25].

On this basis, it is clear that Nrf2 is now correctly recognized as the key cellular defence system against oxidative and xenobiotic stresses. Such a crucial event is able to upregulate the synthesis of relevant enzymes.

\subsection{The Reactivation of the Innate Defence System Leads to the Synthesis of a Number of Antioxidant Enzymes Able to Counteract the Chronic Oxidative Stress}

a) Activation of the gamma-glutamyl-cysteine ligase and of GSH synthase allows a marked increase of the GSH intracellular level. The enhanced GSH/GSSG ratio allows an important protection against ROS.

b) Activation of the synthesis of antioxidant enzymes able to detoxify an excess of ROS such as catalase, SOD, GSH-peroxidases, GSH-reductase, NADPH-quinone oxidoreductase (NQO1), Cytochrome P450 monooxygenase system and HSP70.

c) The upregulation of Heme-oxygenase-1 (HO-1) is also very protective and the trace of $\mathrm{CO}$ in combination with NO allows vasodilation of ischemic tissues.

d) The enhancement of the synthesis and levels of phase II enzymes such as GSH S-transferases, UDP-glucuronosyltransferases, N-acetyltransferases and sulfotransferases.

e) Inhibition of cytokine-mediated inflammation via the induction of leukotriene B4 reductase.

f) Reducing iron overload and subsequent oxidative stress induced via elevated ferritin and bilirubin as a lipophilic antioxidant.

g) The repetition of graduated small oxidative stresses induces a multiform adaptive response. Moreover, during the ozone-therapy sessions there is an increased release of adrenocorticotrophic hormone, followed by cortisol 
from the cortex of the adrenal glands as a consequence of the liberation of corticotrophin releasing factor from the hypothalamus [20]. Such a response is responsible for an improved feeling of well-being reported by the majority of patients.

The efficacy of the mentioned orthodox drugs associated with the safe and valid support of the ozonated autohaemotherapy proves that the concept of integrated medicine is the best combination because it correctly associates suitable drugs with the critical stimulus of reactivating the natural defences.

\subsection{The Absolute Lack of Toxicity of Ozone-Therapy}

Gaseous ozone can be harmful at even low concentrations of part per million, affecting especially the eyes and respiratory systems. Administration of ozone by aerosol is toxic and must be avoided, as well as the intravenous administration of the oxygen-ozone gas mixture. On the contrary, very small and precisely determined ozone dosages during ozone-therapy do not procure any acute or late side effects. In fact, addition of ozone to blood happens ex vivo and the minimal amount of ozone acts as a pro-drug and within 2 - 3 min is fully exhausted in small parts by the plasma antioxidants and by generation of $\mathrm{H}_{2} \mathrm{O}_{2}$ and alkenals [27-29]. The performance of ozonetherapy twice weekly for at least five months (about 40 sessions) also allows to improve the vascular system and to enhance the oxygenation of ischemic tissues. Moreover, such a bio-oxidative procedure, well known as ozonated autohemotherapy, can be continued with a weekly session for life with an excellent compliance of patients [30].

\section{REFERENCES}

[1] Munzel, T., Gori, T., Bruno, R.M. and Taddei, S. (2010) Is oxidative stress a therapeutic target in cardiovascular disesase? European Heart Journal, 31, 2741-2749. doi:10.1093/eurheartj/ehq396

[2] Gori, T. and Munzel, T. (2011) Oxidative stress and endothelial dysfunction: Therapeutic implications. Annals of Medicine, 43, 259-272. doi:10.3109/07853890.2010.543920

[3] Taddei, S., Nami, R., Bruno, R.M., Quatrini, I. and Nuti, R. (2011) Hypertension, left ventricular hypertrophy and chronic kidney disease. Heart Failure Reviews, 16, 615620. doi:10.1007/s10741-010-9197-z

[4] Ghiadoni, L., Taddei, S. and Virdis, A. (2012) Hypertension and endothelial dysfunction: Therapeutic approach. Current Vascular Pharmacology, 10, 42-60. doi:10.2174/157016112798829823

[5] Espinola-Klein, C., Gori, T., Blankenberg, S. and Munzel, T. (2011) Inflammatory markers and cardiovascular risk in the metabolic syndrome. Frontiers in Bioscience: A
Journal and Virtual Library, 16, 1663-1774. doi: $10.2741 / 3812$

[6] Virdis, A., Duranti, E. and Taddei, S. (2011) Oxidative stress and vascular damage in hypertension: Role of angiotensin II. International Journal of Hypertension, Article ID: 916310. doi:10.4061/2011/916310

[7] Haas, B., Schlinkert, P., Mayer, P. and Eckstein, N. (2012) Targeting adipose tissue. Diabetology \& Metabolic Syndrome, 4, 43. doi:10.1186/1758-5996-4-43

[8] Droge, W. (2002) Free radicals in the physiological control of cell function. Physiological Reviews, 82, 47-95.

[9] Segal, B.H., Grimm, M.J., Khan, A.N.H., Han, W. and Blackwell, T.S. (2012) Regulation of innate immunity by NADPH oxidase. Free Radical Biology and Medicine, 53, 72-80. doi:10.1016/j.freeradbiomed.2012.04.022

[10] Valko, M., Leibfritz, D., Moncol, J., Cronin, M.T.D., Mazur, M. and Telser, J. (2007) Free radicals and antioxidants in normal physiological functions and human disease. The International Journal of Biochemistry \& Cell Biology, 39, 44-84. doi:10.1016/j.biocel.2006.07.001

[11] Sesso, H.D., Buring, J.E., Christen, W.G., Kurth, T., Belanger, C., MacFadyen, J., Bubes, V., Manson, J.E., Glynn, R.J. and Gaziano, J.M. (2008) Vitamins E and C in the prevention of cardiovascular disease in men: The Physicians' health study II randomized controlled trial. $J A M A$, 300, 2123-2133. doi:10.1001/jama.2008.600

[12] Firuzi, O., Miri, R., Tavakkoli, M. and Saso, L. (2011) Antioxidant therapy: Current status and future prospects. Current Medicinal Chemistry, 18, 3871-3888. doi:10.2174/092986711803414368

[13] Candelario-Jalil, E., Mohammed-Al-Dalain, S., Fernandez, O.S., Menendez, S., Pérez-Davison, G., Merino, N., Sam, S. and Ajamieh, H.H. (2001) Oxidative preconditioning affords protection against carbon tetrachlorideinduced glycogen depletion and oxidative stress in rats. Journal of Applied Toxicolicology, 21, 297-301. doi:10.1002/jat.758

[14] Tylicki, L., Nieweglowski, T., Biedunkiewicz, B., Chamienia, A., Debska-Slizien, A., Aleksandrowicz, E., Lysiak-Szydlowska, W. and Rutkowski, B. (2003) The influence of ozonated autohemotherapy on oxidative stress in hemodialyzed patients with atherosclerotic ischemia of lower limbs. International Journal of Artificial Organs, 26, 297-303.

[15] Di Paolo, N., Bocci, V., Salvo, D.P. and Garosi, G. (2005) Extracorporeal blood oxygenation and ozonation (EBOO): A controlled trial in patients with peripheral artery disease. International Journal of Artificial Organs, 28, 10391050.

[16] Bocci, V., Zanardi, I. and Travagli, V. (2011) Ozone acting on human blood yields a hormetic dose-response relationship. Journal of Translational Medicine, 9, 66. doi:10.1186/1479-5876-9-66

[17] Nakao, A., Faleo, G., Nalesnik, M.A., Seda-Neto, J., Kohmoto, J. and Murase, N. (2009) Low-dose carbon monoxide inhibits progressive chronic allograft nephropathy and restores renal allograft function. American Journal of Physiology Renal Physiology, 297, F19-F26. doi:10.1152/ajprenal.90728.2008 
[18] Martelli, A., Testai, L., Breschi, M.C., Blandizzi, C., Virdis, A., Taddei, S. and Calderone, V. (2010) Hydrogen sulphide: Novel opportunity for drug discovery. Medicinal Research Reviews, 32, 1093-1130. doi:10.1002/med.20234

[19] Bocci, V., Borrelli, E., Travagli, V. and Zanardi, I. (2009) The ozone paradox: Ozone is a strong oxidant as well as a medical drug. Medicinal Research Reviews, 29, 646-682. doi:10.1002/med.20150

[20] Bocci, V. (2012) How a calculated oxidative stress can yield multiple therapeutic effects. Free Radical Research, 46, 1068-1075. doi:10.3109/10715762.2012.693609

[21] Motohashi, H. and Yamamoto, M. (2004) Nrf2-Keap1 defines a physiologically important stress response mechanism. Trends in Molecular Medicine, 10, 549-557. doi:10.1016/j.molmed.2004.09.003

[22] Zhang, D.D. (2006) Mechanistic studies of the Nrf2Keap1 signaling pathway. Drug Metabolism Reviews, 38, 769-789. doi:10.1080/03602530600971974

[23] Sagai, M. and Bocci, V. (2011) Mechanisms of action involved in ozone therapy: Is healing induced via a mild oxidative stress? Medical Gas Research, 1, 29. doi:10.1186/2045-9912-1-29

[24] Pecorelli, A., Bocci, V., Acquaviva, A., Belmonte, G., Gardi, C., Virgili, F., Ciccoli, L. and Valacchi, G. (2013) Nrf2 activation is involved in ozonated human serum upregulation of HO-1 in endothelial cells. Toxicology and Applied Pharmacology, 267, 30-40. doi:10.1016/j.taap.2012.12.001

[25] Taguchi, K., Fujikawa, N., Komatsu, M., Ishii, T., Unno, M., Akaike, T., Motohashi, H. and Yamamoto, M. (2012) Keap1 degradation by autophagy for the maintenance of redox homeostasis. Proceedings of the National Academy of Sciences of USA, 109, 13561-13566. doi:10.1073/pnas.1121572109

[26] Taguchi, K., Motohashi, H. and Yamamoto, M. (2011) Molecular mechanisms of the Keap1-Nrf2 pathway in stress response and cancer evolution. Genes Cells, 16, 123-140. doi:10.1111/j.1365-2443.2010.01473.x.

[27] Jacobs, M.T. (1982) Untersuchung uber zwishenfalle und typische komplikationen in der ozon-sauerstofftherapie. OzoNachrichten, 5, 1-5.

[28] Travagli, V., Zanardi, I., Silvietti, A. and Bocci, V. (2007) A physicochemical investigation on the effects of ozone on blood. International Journal of Biological Macromolecules, 41, 504-511. doi:10.1016/j.ijbiomac.2007.06.010

[29] Travagli, V., Zanardi, I., Bernini, P., Nepi, S., Tenori, L. and Bocci, V. (2010) Effects of ozone blood treatment on the metabolite profile of human blood. International Journal of Toxicology, 29, 165-174. doi:10.1177/1091581809360069

[30] Bocci, V., Zanardi, I. and Travagli V. (2011) Ozone: A new therapeutic agent in vascular diseases. American Journal of Cardiovascular Drugs, 11, 1-10. doi:10.2165/11539890-000000000-00000 